\title{
Information needs of francophone health care professionals and the public with regard to medical assistance in dying in Quebec: a qualitative study
}

\author{
Antoine Boivin MD PhD, François-Pierre Gauvin PhD, Geneviève Garnon PhD, Agustina Gancia PhD, \\ Ghislaine Rouly, Isabelle Marcoux PhD, Pascale Lehoux PhD
}

Abstract

Background: In 2016, the Canadian government legalized medical assistance in dying (MAiD) for adults with terminal illness. The objective of this study was to explore the information needs of health care professionals and members of the public regarding MAiD.

Methods: This was a qualitative study involving a 1-day face-to-face forum followed by a 3-week online forum across the province of Quebec conducted in June 2016. French-speaking participants targeted for the study included members of the public (citizens, patients and caregivers) and health care professionals. Participants were recruited through calls for applications to a patient partner network and via social media, and through mailing lists of partner professional and community organizations across Quebec. We used a purposeful sampling strategy to recruit a diverse group of participants. In the forums, deliberations were prompted by short informational videos about MAiD. We performed a thematic analysis to identify key information needs.

Results: Fifty members of the public and 35 health care professionals participated. Forty-three people participated in the face-to-face meeting, and 42 people participated online. Participants identified 32 information needs (22 expressed by both members of the public and health care professionals, and 10 specific to members of the public) regarding the definition of MAiD, eligibility criteria, and documenting and evaluating practices. Information needs varied along different stages of the patient's journey. Participants expressed the need to be informed about issues that go beyond the medical and legal aspects of MAiD (e.g., relational, symbolic, psychological and spiritual aspects).

Interpretation: The findings show that health care professionals and members of the public have common information needs regarding MAiD and seek information on the relational, emotional and symbolic aspects of this practice. These findings call for concerted efforts to build a common information base - covering dimensions that go beyond the medical and legal aspects of MAiD — to facilitate informed conversations among patients, health care professionals and members of the public.

I n 2014, the province of Quebec adopted the Act

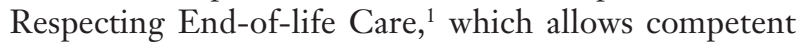
adults with terminal illness to request medical assistance in dying (MAiD). Medical assistance in dying is defined as "care consisting in the administration by a physician of medications or substances to an end-of-life patient, at the patient's request, in order to relieve their suffering by hastening death." At the federal level, the Supreme Court of Canada, in Carter v. Canada, declared that Criminal Code prohibition of MAiD was in violation of the Canadian Charter of Rights and Freedoms. ${ }^{2}$ In June 2016, the Canadian government passed federal legislation (Bill C-14) amending the Criminal Code to allow MAiD across the country. ${ }^{3}$

Patients' preferences toward end-of-life care have been studied abundantly. ${ }^{4-6}$ However, an important degree of confusion regarding MAiD has been noted among members of the public and professionals. ${ }^{7-9}$ A recent study showed that
Quebec health care professionals confuse MAiD with other end-of-life practices, such as treatment withdrawal and the use of drugs for symptom management. ${ }^{10}$ Yet the literature addressing information needs about MAiD remains scarce and rarely focuses on the respective needs of patients and professionals. ${ }^{11-17}$ This knowledge gap is a barrier for the development of relevant and effective public information strategies on MAiD. This study aimed to explore the information needs of health care professionals and members of the public regarding MAiD.

\section{Competing interests: None declared.}

This article has been peer reviewed.

Correspondence to: Antoine Boivin, Antoine.boivin@umontreal.ca CMAJ Open 2019. DOI:10.9778/cmajo.20180155 


\section{Methods}

\section{Design}

We conducted a qualitative study using deliberation for data elicitation and thematic content analysis for data synthesis. ${ }^{18}$ Deliberation refers to a dialogue that involves the careful weighing of reasons for or against a proposition. ${ }^{19}$ Deliberative forums go beyond traditional public consultation by incorporating at least 3 key elements: 1) provision of information to participants about the issue being discussed, 2) opportunity for interactive discussion among participants and 3) an explicit process for collecting individual or collective input. ${ }^{20}$ Deliberation creates an opportunity to move away from raw public opinions elicited by traditional consultation mechanisms about complex health care system issues toward more informed and responsible public judgment. ${ }^{21}$

To balance depth and geographical scope, we conducted deliberative forums in 2 formats: a 1-day face-to-face forum with participants from the greater Montréal area held in a public community building in May 2016 and a 3-week online forum in June 2016 with participants from across the province of Quebec, the only Canadian province where MAiD was legal at the time of the study, in order to extend the forum to participants living in other urban and rural areas of Quebec. The forums were conducted in French. The design of the forums was based on previous deliberation studies. ${ }^{22,23}$ The forum discussions were introduced by short videos (about 4-5 min) produced with legal and medical experts that were structured around the following topics: 1) definition of MAiD, 2) eligibility criteria, 3) how MAiD is practised and 4) how MAiD practices are evaluated and monitored. The purpose of the videos was to prompt discussion about what participants knew or did not know, as well as what additional information they needed. The videos are available online at https://ceppp.ca/fr/que-doit-on-savoir-sur -laide-medicale-a-mourir/.

The face-to-face forum was moderated by an independent professional female moderator hired from a not-for-profit organization with expertise in citizen engagement (Institut du Nouveau Monde). She introduced the topics during the plenary session, before participants discussed them in small groups. The participants then reunited to provide feedback. The online forum was moderated by 2 independent male and female moderators from the same organization, who introduced the videos and topics. It lasted 3 weeks as each theme/ video was introduced sequentially, with a few days between each to allow for asynchronous discussion among participants. During the first half of the online forum, participants were given access to the information videos and were asked to comment on their information needs. After each week, the moderators produced a synthesis of discussions with outstanding questions to be discussed with participants. The moderators proactively ensured that all participants provided input and that all topics were explored in depth. The forum was hosted on the deliberative platform Agora, supported by the Institut du Nouveau Monde. No repeat or follow-up interviews were conducted.

\section{Data collection}

For each of the 4 themes presented in the videos, participants were asked to reflect on 2 questions: what information was new to them and what questions were left unanswered. We used 4 methods to collect data on the deliberation content and process during the forums. For the face-to-face forums, we audio recorded the participants' discussions, and "placemats" were used by participants to write and compile individual and collective responses. For the online forums, written exchanges during the online forum and notes from 2 nonparticipant observers (G.G. and F.-P.G.) were used.

\section{Participants}

Participants targeted for the study included members of the public (citizens, patients and caregivers) and health care professionals (physicians, nurses, pharmacists, social workers, ethicists and managers). We used 2 strategies to recruit participants: a call for applications to the patient partner network of the Patient Partnership and Collaboration Unit at the Faculty of Medicine, Université de Montréal, and a call for applications via social media (Twitter and Facebook) and mailing lists of partner professional organizations and community organizations (organizations representing patients and older adults, and organizations promoting citizen engagement) across Quebec. Interested candidates were asked to submit their application online. Health care professionals completed the same application process as members of the public but were not asked to provide their annual family income. We used a purposeful sampling strategy to recruit a diverse group of members of the public based on the following criteria: age, sex, socioeconomic status, region, health status, personal experience with end-of-life care as a patient or caregiver, and attitude toward MAiD. Two members of the research team (G.G. and F.-P.G.) mapped participants' individual characteristics on a chart, and the balance of all participants' characteristics were reviewed with a third research team member (A.B.) to ensure adequate representation of each subgroup. Health care professionals were also selected to include a diversity of participants based on health discipline, experience with endof-life care, region and attitude toward MAiD. Participants received a fixed amount of $\$ 120$ as compensation for their travel and time.

\section{Data analysis}

We used qualitative thematic content analysis to synthesize the key information needs that emerged from the forums and to identify key principles that could guide a public information strategy on MAiD. ${ }^{24}$ We used thematic content analysis because we sought categories of themes and questions raised by participants that could drive information strategies. We used a combination of deductive approach (using broad categories related to the patient's journey) and inductive approach (driven by data using emerging categories). ${ }^{24}$ All data were coded by 2 doctoral-level research team members (G.G. and F.-P.G.) and reviewed during analytical meetings with other team members to further refine analyses. Disagreements between the coders were resolved through discussion with the 
broader research team. The analyses paid particular attention to the convergence and divergence between the perspectives of members of the public and health care professionals. Participants were sent a short synthesis of the data and were asked to provide feedback. We used inductive thematic saturation to inform the completion of data analysis when no more themes emerged. ${ }^{25} \mathrm{We}$ conducted qualitative data analysis using NVivo software (QSR International).

\section{Ethics approval}

The research ethics committee of the Centre hospitalier de l'Université de Montréal approved and monitored this project. This work follows the Consolidated Criteria for Reporting Qualitative Studies 32-item checklist. ${ }^{26}$

\section{Results}

We received 84 applications from members of the public and 42 applications from health care professionals. We invited 50 and 35 people, respectively, to participate. No selected candidates refused to participate or dropped out of the study. Forty-three people (23 members of the public and 20 health care professionals) participated in the face-to-face forum, and 42 people $(27$ members of the public and 15 health care professionals) participated online. Thirty-nine members of the public $(78 \%)$ had personal experience as patients with chronic or incurable illness, and $33(66 \%)$ had played the role of caregiver to a patient with chronic or incurable disease. Professionals included physicians (4 [11\%]), nurses (7 [20\%]), a pharmacist (3\%), a manager (3\%), a clinical ethicist (3\%) and allied health care professionals such as social workers, psychologists, respiratory therapists, spiritual workers and occupational therapists $(21[60 \%])$. Participants' characteristics as reported in the application process are provided in Table 1.

\section{Overview of information needs}

Our forums revealed 32 information needs, 22 of which were expressed by both members of the public and health care professionals, and 10 of which were specific to members of the public (none were specific to health care professionals). The information needs by stage of the patient's journey along with illustrative quotes are presented in Table 2.

\section{Reflections and discussions as the end of life approaches}

Before a diagnosis of incurable disease, information needs focused on positioning MAiD among other end-of-life practices and concepts including palliative care, palliative sedation, euthanasia and assisted suicide. Confusion was expressed by members of the public about the definition of MAiD.

Participants expressed a general concern regarding access to MAiD in different end-of-life care settings (e.g., home, palliative care unit, nursing home), since this might affect patients' decision to receive MAiD. Because provincial and federal legislations on MAiD were adopted separately, many participants wondered how the 2 laws would align and which one would prevail in the case of disagreement.
2. Formulating a request for medical assistance in dying Participants wondered whether the option of MAiD could put pressure on vulnerable patients and where MAiD would fit along range of options of medical end-of-life care: early, as an option within the continuum of end-of-life care, or later, when there is no other active treatment option left. Furthermore, participants' information needs focused on the support provided to patients for decision-making. Medical assistance in dying cannot be requested through advance directives, which raised questions about substituted consent for incompetent patients (e.g., those with Alzheimer disease), as members of the public initially believed that patients with degenerative disease could request MAiD before cognitive declines prevented them from doing so. Finally, given the fact that end-of-life care often involves

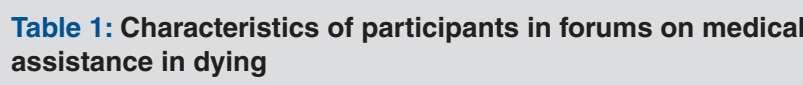

\begin{tabular}{|ccc}
\hline & \multicolumn{2}{c}{ No. (\%) of participants } \\
\cline { 2 - 3 } & Members of the & Health care \\
Characteristic & public & professionals \\
& $n=50$ & $n=35$
\end{tabular}

Sex

\begin{tabular}{|c|c|c|}
\hline Male & $14(28)$ & $5(14)$ \\
\hline Female & $36(72)$ & $30(86)$ \\
\hline \multicolumn{3}{|l|}{ Age, yr } \\
\hline $18-39$ & - & $12(34)$ \\
\hline $18-45$ & $8(16)$ & - \\
\hline $40-50$ & - & $6(17)$ \\
\hline $46-64$ & $20(40)$ & - \\
\hline$\geq 51$ & - & $17(49)$ \\
\hline$\geq 65$ & $22(44)$ & - \\
\hline \multicolumn{3}{|c|}{ Annual family income, \$ } \\
\hline$<20000$ & $8(16)$ & NA \\
\hline 20 000-39 999 & $16(32)$ & NA \\
\hline $40000-59999$ & $12(24)$ & NA \\
\hline$\geq 60000$ & $7(14)$ & NA \\
\hline No answer & $7(14)$ & NA \\
\hline \multicolumn{3}{|c|}{ Attitude toward MAiD } \\
\hline Very favourable & $18(36)$ & $9(26)$ \\
\hline Favourable & $22(44)$ & $15(43)$ \\
\hline Uncertain & $6(12)$ & $8(23)$ \\
\hline Unfavourable & $2(4)$ & $3(9)$ \\
\hline No answer & $2(4)$ & $0(0)$ \\
\hline \multicolumn{3}{|l|}{ Region } \\
\hline Urban & $28(56)$ & $21(60)$ \\
\hline Semiurban & $16(32)$ & $14(40)$ \\
\hline Rural & $6(12)$ & $0(0)$ \\
\hline
\end{tabular}


interdisciplinary teams, participants wanted information about the roles of professionals other than physicians in MAiD.

\section{Evaluating requests}

Information needs became more procedural at this stage and focused on evaluating patients' eligibility and alignment with legal criteria. Members of the public expressed concern relating to the expected delays for evaluation and whether a request from a patient experiencing psychological distress would be evaluated, considering that some patients could rapidly become incapable of giving consent.

Many participants argued that interpreting certain eligibility criteria would be challenging and would require interdisci- plinary expertise beyond that of physicians. Some wondered whether conscientious objection applied to all members of the care team or only to physicians. Questions were raised about available resources for patients who meet legal criteria but whose request is denied because of conscientious objection. How disagreement and conflicts between patients, family members and professionals get resolved remained a question.

\section{Communicating decisions}

Members of the public wondered whether patients could reapply with a different physician after a rejected request, and how reluctance on the part of the physician would be dealt with. Given concerns about the impact of a "communication

Table 2 (part 1 of 2): Information needs of the public and health care professionals regarding medical assistance in dying

\begin{tabular}{|c|c|c|c|}
\hline $\begin{array}{l}\text { Stage of patient's } \\
\text { journey }\end{array}$ & $\begin{array}{l}\text { Need(s) expressed by } \\
\text { members of the public and } \\
\text { professionals }\end{array}$ & $\begin{array}{l}\text { Need(s) expressed by members } \\
\text { of the public only }\end{array}$ & Illustrative quote \\
\hline $\begin{array}{l}\text { 1. Reflections and } \\
\text { discussions as } \\
\text { end of life } \\
\text { approaches }\end{array}$ & $\begin{array}{l}\text { Where can MAiD be } \\
\text { delivered? } \\
\text { How does MAiD align with } \\
\text { current (and future) laws? } \\
\text { How should the eligibility } \\
\text { criteria be interpreted? }\end{array}$ & $\begin{array}{l}\text { How is MAiD distinguished from } \\
\text { other end-of-life practices? } \\
\text { What are the eligibility criteria for } \\
\text { MAiD? } \\
\text { How can a patient express his/her } \\
\text { last wishes and ensure that they } \\
\text { will be respected? }\end{array}$ & $\begin{array}{l}\text { "It seems that every time they come up with a } \\
\text { new term, there is a whole new semantic field } \\
\text { appearing, which escapes ordinary mortals } \\
\text { that are patients." (Public) } \\
\text { "Currently, the situation is ambiguous as to the } \\
\text { role and obligations of some end-of-life care } \\
\text { settings that seem to be resisting the law." } \\
\text { (Public) } \\
\text { "Who determines the time it takes for a patient } \\
\text { to be considered at the end of life?" (Public) }\end{array}$ \\
\hline $\begin{array}{l}\text { 2. Formulating } \\
\text { request for MAiD }\end{array}$ & $\begin{array}{l}\text { Who can make a request? } \\
\text { To whom can a request be } \\
\text { made? } \\
\text { Is psychosocial support } \\
\text { available when a patient is } \\
\text { considering a request? } \\
\text { How can the "openness" to } \\
\text { initiate a conversation about } \\
\text { MAiD with relatives and health } \\
\text { care professionals be created? } \\
\text { Where does MAiD fit along } \\
\text { the full range of end-of-life } \\
\text { care options? }\end{array}$ & $\begin{array}{l}\text { When can a request for MAiD be } \\
\text { made? }\end{array}$ & $\begin{array}{l}\text { "What are the dispositions of the law for } \\
\text { minors, dementia and all those who are not } \\
\text { capable to consent? Can the representative of } \\
\text { a patient (legal representative, family council, } \\
\text { etc.) apply for MAiD?" (Professional) } \\
\text { "How can we create an openness between } \\
\text { professionals and patients to properly discuss } \\
\text { all these choices?" (Public) } \\
\text { "Will psychological support be provided? } \\
\text { Deciding of the day and time of one's death is } \\
\text { somehow empowering but nevertheless } \\
\text { distressing." (Public) }\end{array}$ \\
\hline $\begin{array}{l}\text { 3. Evaluating } \\
\text { requests }\end{array}$ & $\begin{array}{l}\text { How are requests evaluated } \\
\text { and by whom? } \\
\text { If a physician refuses to } \\
\text { evaluate a request, how will } \\
\text { the request be transferred to } \\
\text { another physician? } \\
\text { What is the scope of } \\
\text { conscientious objection to } \\
\text { MAiD? } \\
\text { If there is a disagreement in } \\
\text { the evaluation of the request, } \\
\text { is there a mediation process? }\end{array}$ & $\begin{array}{l}\text { What are the expected delays for } \\
\text { evaluating a patient's request? } \\
\text { Can a patient have access to } \\
\text { MAiD if he/she is experiencing } \\
\text { psychological suffering only? }\end{array}$ & $\begin{array}{l}\text { "What is acceptable in terms of reasonable } \\
\text { delay? ... If his condition worsens, can the } \\
\text { patient get [MAiD] imminently?" (Public) } \\
\text { "If a physician refuses to practise MAiD and } \\
\text { relies on the chief executive officer [to forward } \\
\text { the request to another physician], how will the } \\
\text { request be assessed in reasonable time? This } \\
\text { is an urgent request since, to meet criteria, } \\
\text { one must be dying!" (Professional) }\end{array}$ \\
\hline $\begin{array}{l}\text { 4. Communicating } \\
\text { decisions }\end{array}$ & $\begin{array}{l}\text { How are decisions } \\
\text { communicated in the case of } \\
\text { both approval and refusal? }\end{array}$ & $\begin{array}{l}\text { If a patient changes his/her mind } \\
\text { after the request is accepted, can } \\
\text { he/she reapply? } \\
\text { Is it possible for a patient to apply } \\
\text { to another physician if a first } \\
\text { request has been refused? }\end{array}$ & $\begin{array}{l}\text { "Will it be possible to see another doctor, if, for } \\
\text { instance, I don't meet all the criteria? Is there } \\
\text { some form of mediation process?" (Public) }\end{array}$ \\
\hline
\end{tabular}


Table 2 (part 2 of 2): Information needs of the public and health care professionals regarding medical assistance in dying

\begin{tabular}{|c|c|c|c|}
\hline $\begin{array}{l}\text { Stage of patient's } \\
\text { journey }\end{array}$ & $\begin{array}{l}\text { Need(s) expressed by } \\
\text { members of the public and } \\
\text { professionals }\end{array}$ & $\begin{array}{l}\text { Need(s) expressed by members of } \\
\text { the public only }\end{array}$ & Illustrative quote \\
\hline 5. Delivering MAiD & $\begin{array}{l}\text { Are the necessary resources } \\
\text { available in all institutions } \\
\text { (and in all regions) to provide } \\
\text { MAiD? } \\
\text { What is the waiting time for } \\
\text { practising MAiD once a } \\
\text { request is accepted? } \\
\text { What is the role of the health } \\
\text { care team and relatives } \\
\text { during the process? } \\
\text { What support is provided to } \\
\text { the care team and relatives } \\
\text { before, during and after the } \\
\text { administration of MAiD? } \\
\text { What are the possible harms } \\
\text { and side effects associated } \\
\text { with administering MAiD? } \\
\text { What measures are in place } \\
\text { to preserve the } \\
\text { confidentiality of MAiD? } \\
\text { How can the process of } \\
\text { delivering MAiD be } \\
\text { humanized? }\end{array}$ & $\begin{array}{l}\text { How can continuous } \\
\text { communication between the } \\
\text { patient and his/her physician, from } \\
\text { the moment a request is made to } \\
\text { the moment MAiD is delivered, be } \\
\text { ensured? }\end{array}$ & $\begin{array}{l}\text { "In a hospital, the doctor often changes every } \\
\text { week. Several doctors may see the patient, } \\
\text { and the interviews are quite short. How can } \\
\text { we make sure that [the dialogue] will be done } \\
\text { to the patient's satisfaction?" (Public) } \\
\text { "Where are the interdisciplinary team and, } \\
\text { especially, the relatives? Are they excluded?" } \\
\text { (Public) } \\
\text { "Do we have support after? Are there any } \\
\text { resources after all these steps? It is a pretty } \\
\text { traumatic way to end a life! Nothing is } \\
\text { mentioned in the law, as much for the health } \\
\text { professionals as for the patients and their } \\
\text { relatives. I know there is an interdisciplinary } \\
\text { support group for MAiD ... but is it functional? } \\
\text { (Professional) } \\
\text { "What are these drugs [used for MAiD]? Most } \\
\text { importantly, what effect do they have on vital } \\
\text { organs and on the brain? How can we } \\
\text { measure the level of consciousness? Studies } \\
\text { have shown that patients in a coma can feel } \\
\text { pain even if they look peaceful on the outside!" } \\
\text { (Public) } \\
\text { "Is the injection method really foolproof? Could } \\
\text { it happen, during the process, that something } \\
\text { doesn't work? 'We thought the patient was } \\
\text { dying,' but a problem occurs! Are there ways to } \\
\text { solve these kinds of problems? (Professional) } \\
\text { "How can a hospital medical environment } \\
\text { provide a meaningful environment for the } \\
\text { patient receiving MAiD? For instance, would } \\
\text { candles, usually not allowed in hospitals, be } \\
\text { allowed for MAiD?" (Professional) }\end{array}$ \\
\hline $\begin{array}{l}\text { 6. Documenting } \\
\text { and evaluating } \\
\text { practices }\end{array}$ & $\begin{array}{l}\text { Who is evaluated and } \\
\text { accountable? } \\
\text { How will the results of the } \\
\text { evaluation be made public } \\
\text { (and what will they be used } \\
\text { for)? }\end{array}$ & $\begin{array}{l}\text { Who evaluates the practices and } \\
\text { how? }\end{array}$ & $\begin{array}{l}\text { "The Act [Respecting End-of-life Care] creates } \\
\text { a Commission on End-of-Life Care for the } \\
\text { whole province, but each institution does not } \\
\text { appear to have any evaluation or control } \\
\text { mechanism other than the Council of } \\
\text { Physicians, Dentists and Pharmacists of } \\
\text { Quebec." (Public) } \\
\text { "What are the obligations imposed on the } \\
\text { [health care] institution with regard with the } \\
\text { quality of the patient's environment? How will } \\
\text { a calm and respectful environment be ensured } \\
\text { for patients and their relatives, just like in } \\
\text { palliative care units?" (Professional) } \\
\text { "What are the consequences for the physician } \\
\text { if the Commission on End-of-Life Care judges } \\
\text { that he/she made a mistake?" (Public) } \\
\text { "Ultimately, will [the Commission] only give us } \\
\text { statistics on the places where there is more } \\
\text { MAiD and where there is less?" (Public) }\end{array}$ \\
\hline
\end{tabular}

protocol" on the therapeutic alliance, both professionals and members of the public wondered whether such a protocol would be available to help health care professionals announce the evaluation results, particularly in the case of refusal. Par- ticipants expected detailed explanations justifying MAiD request decisions, as well as information on alternative care, assuming that a request may be the expression for unmet support needs (e.g., psychological support). 


\section{Delivering medical assistance in dying}

How communication between the patient and the physician would be ensured between approval and administration of MAiD was formulated more as a preoccupation than a question by both health care professionals and members of the public. Concerns were raised about the continuity of palliative care and psychosocial support to patients, relatives and the health care team between approval and administration of MAiD, as well as which measures would be adopted to ensure confidentiality.

Many participants mentioned the lack of a clear framework as to how information would be shared with relatives and other members of the interdisciplinary team.

Questions were raised about the delivery of MAiD, possible medical complications and how MAiD could be approached with humanity and respect, as opposed to being framed as a technical procedure. Many participants indicated that MAiD is described in the law as a clinical, legal and administrative process, which led to questions about the possibility of personalizing the physical environment by incorporating music, religious rituals and/or symbols.

\section{Documenting and evaluating practices}

Information needs after the administration of MAiD focused on evaluation and accountability of the physician, health care team or institution. Participants wondered who evaluates practice (both from a technical and humanity standpoint), and how. The responsibilities of health care institutions, professional colleges and the provincial Commission on End-of-Life Care raised questions around the presence of potential conflicts of interest and the type of sanctions following malpractice. Finally, participants wished to know how the evaluation results would be made public and for what use.

\section{Interpretation}

In this qualitative study assessing the information needs around MAiD from the perspective of health care professionals and members of the public, we identified 3 key findings: 1) the majority of information needs are common to health care professionals and members of the public, 2) information needs evolve along the patient's journey and 3 ) information needs go beyond the medical and legal aspects of MAiD. Participants highlighted the need to discuss the "human" dimensions of MAiD, including its relational, symbolic, psychological and spiritual aspects, as opposed to a narrow focus on the technical dimensions of the practice. Although some identified information needs are straightforward to address (e.g., definitions and legal criteria), others are more complex (e.g., wait time and availability of MAiD in specific regions).

Our findings resonate with a growing literature on the public understanding of MAiD, euthanasia and end-of-life care, which have frequently highlighted confusion among different end-oflife practices. ${ }^{10,27}$ Although the existing literature has most often focused on confusion regarding definitions and labelling of different end-of-life practices, our study highlights other informa- tion needs with regard to the practical and symbolic aspects of the MAiD decision process, practice and evaluation.

The finding of common information needs among health care professionals and the public to support informed conversations and shared decision-making is important given that current information strategies are usually focused on professionals or patients separately. In addition to medical and legal criteria, both groups require information on the more human aspects of MAiD. Our findings call for greater collaboration between government, public media, professional bodies, educational institutions, health care institutions, researchers, patient organizations and other civil societies to align their information strategies and meet specific information needs at key junctions of patients' journeys.

Our study raised 2 issues that may warrant further investigation: a need to explore how information needs evolve along different illness trajectories (e.g., chronic illness v. acute lifethreatening conditions $)^{28}$ and a need to identify how to optimally package information to support individual reflections, meaningful conversations with relatives and health care professionals, and decisions about MAiD. This appears particularly challenging given the full range of information needs identified in the current project. Also challenging is the need to package such complex and sensitive information for people with varying levels of literacy. ${ }^{29}$

\section{Limitations}

Although we did not seek to compare the face-to-face and online deliberations, a few differences in group interactions and dynamics were noted by the research team, which may have affected the results. We observed that face-to-face deliberation was more interactive, with participants building on each other's arguments (as per deliberation theory), whereas online deliberation appeared less conducive to participation by more passive participants. As such, online deliberation did not act as a substitute for face-to-face deliberation and may have limited in-depth input from rural participants. Another limitation was the challenge of recruiting certain groups of participants, including men, physicians, health care professionals from rural areas and people with unfavourable views toward MAiD. Although patients and health care professionals were part of the research team who framed the questions, our data collection strategy was not piloted, which is a potential limitation. More specifically, it was challenging at times to shift the dynamic from debate (e.g., how should MAiD criteria be adapted?) to dialogue focused on information needs, partly because MAiD is such a highly complex and sensitive topic. These challenges must be overcome in future initiatives to pursue informed conversations about MAiD and end-oflife care in general. Of note, this study was conducted soon after MAiD was legalized in Quebec, and just before it was legalized federally, and we did not formally assess the proportion of participants who had actual experience with this practice. Information needs should distinguish those with and without MAiD practice experience in future studies. The study was conducted only among francophone participants in Quebec, and the results should be compared with those from 
similar assessments in other parts of the country and other cultural groups. Finally, because unique participant identifiers were not included in the coding, quotes could not be attributed to individual participants.

\section{Conclusion}

Health care professionals and members of the public have common information needs regarding MAiD and seek information on the relational, emotional and symbolic aspects of this practice. These findings call for concerted efforts to build a common information base and facilitate informed conversations on end-of-life care among health care professionals, patients and the public.

\section{References}

1. Chapter S32.0001: Act respecting end-of-life care. 2014, c. 2, s. 17. Québec: Les Publications du Québec; updated 2018 Dec. 31. Available: http://legisquebec. gouv.qc.ca/en/pdf/cs/S-32.0001.pdf (accessed 2018 June 12).

2. Baker GR, Fancott C, Judd M, et al. Expanding patient engagement in quality improvement and health system redesign: three Canadian case studies. Healthc Manage Forum 2016;29:176-82.

3. An act to amend the Criminal Code and to make related amendments to other acts (medical assistance in dying), 2016, Bill C-14. Assented June 17, 2016 (42nd Parliament, 1st session). Available: http://laws-lois.justice.gc.ca/PDF/2016_3.pdf (accessed 2018 June 12)

4. Meier EA, Gallegos JV, Thomas LP, et al. Defining a good death (successful dying): literature review and a call for research and public dialogue. Am 7 Geriatr Psychiatry 2016;24:261-71.

5. Freeman S, Smith TF, Neufeld E, et al. The wish to die among palliative home care clients in Ontario, Canada: a cross-sectional study. BMC Palliat Care 2016;15:24.

6. Badrakalimuthu V, Barclay S. Do people with dementia die at their preferred location of death? A systematic literature review and narrative synthesis. Age Ageing 2014;43:13-9.

7. Gentile $\mathrm{D}$. Aide médicale à mourir: le travail de plusieurs médecins critiqué par la Commission. Radio-Canada 2016 June 30. Available: http://ici.radio-canada.ca/ nouvelle/790324/aide-medicale-mourir-medecins-critique-commission-soins-fin -vie (accessed 2018 July 15).

8. Lacoursière A. Aide médicale à mourir : ce n'est pas un bar « ouvert ». La Presse [Montréal] 2016 Jan. 12. Available: www.lapresse.ca/actualites/sante/ 201601/11/01-4938873-aide-medicale-a-mourir-ce-nest-pas-un-bar-ouvert.php (accessed 2018 July 15)

9. Pelchat P. Aide médicale à mourir : les Québécois confus. Le Soleil [Québec] 2013 Sept. 27. Available: www.lesoleil.com/actualite/sante/aide-medicale-a -mourir-les-quebecois-confus-36c7056199ca75b14ac79d593149972d (accessed 2018 July 15).

10. Marcoux I, Boivin A, Arsenault C, et al. Health care professionals' comprehension of the legal status of end-of-life practices in Quebec: study of clinical scenarios. Can Fam Physician 2015;61:e196-203.

11. Emanuel EJ, Onwuteaka-Philipsen BD, Urwin JW, et al. Attitudes and practices of euthanasia and physician-assisted suicide in the United States, Canada, and Europe. FAMA 2016;316:79-90.

12. Lavoie M, Godin G, Vézina-Im LA, et al. Psychosocial determinants of nurses' intention to practise euthanasia in palliative care. Nurs Ethics 2016;23:48-60.

13. Lavoie M, Godin G, Vézina-Im LA, et al. Psychosocial determinants of physicians' intention to practice euthanasia in palliative care. BMC Med Ethics 2015;16:6.

14. Evans L. Nurses' attitudes to assisted suicide: sociodemographic factors. $\operatorname{Br} \mathrm{F}$ Nurs 2015;24:629-32.

15. Claxton-Oldfield S, Miller K. A study of Canadian hospice palliative care volunteers' attitudes toward physician-assisted suicide. Am 7 Hosp Palliat Care 2015;32:305-12.

16. Teisceira-Lessard P. Les Canadiens appuient l'aide à mourir. La Presse [Montréal] 2014 Oct. 9. Available: www.lapresse.ca/actualites/sante/201410/08/01 -4807662-les-canadiens-appuient-laide-a-mourir.php (accessed 2017 Nov. 13).

17. Vézina-Im LA, Lavoie M, Krol P, et al. Motivations of physicians and nurses to practice voluntary euthanasia: a systematic review. BMC Palliat Care 2014;13:20.
18. Bombard Y, Abelson J, Simeonov D, et al. Citizens' perspectives on personalized medicine: a qualitative public deliberation study. Eur 7 Hum Genet 2013; 21:1197-201.

19. Fearon JD. Deliberation as discussion. In: Elster J, editor. Deliberative democracy. Cambridge (UK): Cambridge University Press; 1998:44-68.

20. Yankelovich D, Friedman W, editors. Toward wiser public judgment. Nashville (TN): Vanderbilt University Press; 2011.

21. Bohman J. Public deliberation: pluralism, complexity, and democracy. Cambridge (MA): MIT Press; 1996.

22. Lehoux P, Jimenez-Pernett J, Miller FA, et al. Assessment of a multimediabased prospective method to support public deliberations on health technology design: participant survey findings and qualitative insights. BMC Health Serv Res 2016;16:616.

23. Boivin A, Lehoux P, Burgers J, et al. What are the key ingredients for effective public involvement in health care improvement and policy decisions? A randomized trial process evaluation. Milbank Q 2014;92:319-50.

24. Fereday J, Muir-Cochrane E. Demonstrating rigor using thematic analysis: a hybrid approach of inductive and deductive coding and theme development. Int 7 Qual Methods 2006;5:80-92.

25. Saunders B, Sim J, Kingstone T, et al. Saturation in qualitative research: exploring its conceptualization and operationalization. Qual Quant 2018;52:1893-907.

26. Tong A, Sainsbury P, Craig J. Consolidated criteria for reporting qualitative research (COREQ): a 32-item checklist for interviews and focus groups. Int 7 Qual Health Care 2007;19:349-57.

27. Marcoux I, Mishara BL, Durand C. Confusion between euthanasia and other end-of-life decisions: influences on public opinion poll results. Can $\mathcal{F}$ Public Health 2007;98:235-9.

28. Murray SA, Kendall M, Boyd K, et al. Illness trajectories and palliative care. BM7 2005;330:1007-11

29. Berkman ND, Sheridan SL, Donahue KE, et al. Health literacy interventions and outcomes: an updated systematic review. Evid Rep Technol Assess (Full Rep) 2011;199:1-941.

Affiliations: Centre of Excellence on Partnership with Patients and the Public (Boivin, Gauvin, Garnon, Gancia, Rouly); Department of Family and Emergency Medicine (Boivin), Université de Montréal; Department of Management, Evaluation and Health Policy (Boivin, Lehoux), School of Public Health, Université de Montréal, Montréal, Que.; Interdisciplinary School of Health Sciences (Marcoux), University of Ottawa, Ottawa, Ont.; Department of Health Research Methods, Evidence, and Impact (Gauvin), Centre for Health Economics and Policy Analysis, McMaster University, Hamilton, Ont.

Contributors: Antoine Boivin, François-Pierre Gauvin, Geneviève Garnon, Isabelle Marcoux and Pascale Lehoux conceived the study. Geneviève Garnon, François-Pierre Gauvin, Antoine Boivin and Ghislaine Rouly interpreted the data. Antoine Boivin, Geneviève Garnon and Agustina Gancia drafted the manuscript. All of the authors critically revised the manuscript for important intellectual content, gave final approval of the version to be published and agreed to be accountable for all aspects of the work.

Funding: Antoine Boivin holds the Canada Research Chair in Patient and Public Partnership.

Acknowledgements: The authors thank the members of the scientific committee, David Lussier, geriatrician, Institut universitaire de gériatrie de Montréal, and Pierre Deschamps, lawyer-ethicist, Health Research Group and Law, McGill University, Montréal, for sharing their expertise, as well as the partners who contributed to the implementation of the forums. They highlight the contribution of Malorie Flon and Myriam Fahmy to the facilitation of the face-to-face forum and of Victor Fontaine to the facilitation of the online forum. Finally, the forums would not have been possible without the engagement of citizens, patients, caregivers and health care professionals from across Quebec. The authors thank them very much for sharing their experiences and knowledge.

Supplemental information: For reviewer comments and the original submission of this manuscript, please see www.cmajopen.ca/content/7/2/ E190/suppl/DC1. 